\title{
Intervenção pública dos programas federais de assistência ao homem do campo no município de Aparecida - PB
}

\author{
Intervention public the programs federais of assistance to man the field in the \\ municipality of Aparecida - PB
}

\author{
Francisco Tales da Silva ${ }^{1}$, Alan Dél Carlos Gomes Chaves ${ }^{2}$, Ricardo Ricelli Pereira de Almeida ${ }^{3}$, Eclivaneide Caldas de \\ Abreu Carolino ${ }^{4}$, Josias de Castro Galvão ${ }^{5}$.
}

\begin{abstract}
RESUMO - A intervenção pública realizada no município de Aparecida por meio dos programas do Governo Federal de microcrédito tem a finalidade de fortalecer a economia rural e inserir no campo uma parceira para melhorar as condições de produção e trabalho do homem que vive na zona rural do município. O presente estudo teve como objetivo analisar os investimentos feitos pelos programas de assistência rural, ao homem do campo no município de Aparecida-PB. O método adotado para a pesquisa foi o método dialético, no qual buscou-se investigar essa nova dinâmica ocorrente no campo brasileiro, motivado pelo financiamento do Governo Federal destinado a agricultura familiar com a política do PRONAF. Isso só foi possível através dos seguintes procedimentos de entrevistas semiestruturadas realizadas com os promotores do PRONAF no município de Aparecida sendo eles: o Banco do Nordeste Brasileiro (BNB), Empresa de Assistência Técnica e Extensão Rural (EMATER), Central de Associações de Assentamentos do Alto Sertão Paraibano (CAAASP) e o Sindicato Rural dos Agricultores de Aparecida-PB e também através de questionários aplicados aos agricultores do assentamento Acauã e do PIVAS. O programa oportunizou melhorias no campo de forma significativa para àqueles que realmente acreditaram na proposta do programa, tendo progredido na segurança alimentar da família que passou a produzir mais, na comercialização da produção que possui destinos diversos, mas principalmente ocorre na própria comunidade e isso garante segurança alimentar não só ao produtor, mas para a própria comunidade como um todo.
\end{abstract}

Palavras - chave: PRONAF, agricultura familiar, segurança alimentar e fortalecimento da economia rural.

\begin{abstract}
The public intervention carried out in the city of Aparecida through the federal government microcredit programs is intended to strengthen the rural economy and to create a partnership to improve the conditions of production and work of the people in the rural area of the municipality. This study aimed to analyze the investments made by rural assistance programs to, the peasants in the city of Aparecida-PB. The research adopted the dialectical method, in which we seek to investigate this new dynamic occurring in the Brazilian countryside, motivated with Federal Government funds aimed at family farming with PRONAF policy. It was only made possible through the following semi-structured interviews with PRONAF actors in the city of Aparecida: Banco do Nordeste Brasileiro (BNB), Empresa de Assistência Técnica e extensãoRural (EMATER) Centro de Associações de assentamentos do Alto Sertão Paraibano (CAAASP) and the Rural Farmer's union of Aparecida-PB and also through questionnaires given to farmers of the Acauã settlement and PIVAS. The program provided an opportunity to significantly improve the field to those who really believe in the program proposal and made progress on family food security, which increased production and market destination to several destination, but mainly within the community ensuring food security not only to producers but to the community as a whole.
\end{abstract}

Key words: PRONAF, family agriculture, food security and rural economy strengthening.

\footnotetext{
*Autor para correspondência

Recebido para publicação em 12/03/2014 aprovado em 22/12/2014

${ }^{1}$ Graduado em Geografia - CFP/UFCG; Fone: (83) 99298668; E-mail: t.silva_@outlook.com

${ }^{2}$ Mestre em Sistemas Agroindustriais - CCTA/UFCG; Fone: (83) 96589908; E-mail: alan.delcarlos@ hotmail.com

${ }^{3}$ Graduado em Engenharia Ambiental - CCTA/UFCG; Fone: (83) 99009003; E-mail: ricelli2008@ bol.com.br

${ }^{4}$ Especialista em Educação, Desenvolvimento e Políticas Educativas - ISEC/FSPB; Fone: (83) 81085861; E-mail: eclivaneide@ hotmail.com

${ }^{5}$ Doutor em Geografia pela Universidade Federal do Rio de Janeiro; Fone: (83) 93627465 - E-mail: josiascastro@ uol.com.br
} 


\section{INTRODUÇÃO}

A falta de acesso ao crédito para o pequeno agricultor, somado às insatisfações políticas, originaram revoltas no campo e grandes manifestações, como as marchas para os maiores centros urbanos do país (principalmente até a Esplanada dos Ministérios em Brasília-DF). Ocorreram também inúmeras invasões de propriedades públicas e privadas, reivindicando melhorias para o campo, reforma agrária e políticas públicas para agricultura familiar.

Para amenizar essa insatisfação e revoltas no campo, o Governo Federal foi pressionado a criar políticas públicas para reverter essa conjuntura. Mattos (2001) descreve políticas públicas como sendo as compreendidas de responsabilidade do Estado quanto à implementação e manutenção a partir de um processo de tomada de decisões que envolvem órgãos públicos e diferentes organismo e agentes da sociedade relacionadas a políticas implementadas.

Assim, a política pública deve ser entendida como o Estado em movimento, interagindo com a sociedade e criando oportunidades de distribuição de renda entre sua população, possibilitando assim melhores condições de vida a todos.

A estratégia era fortalecer a agricultura familiar, por meio de muitas metas, como nos lembra Silva (1999).

Definido como uma estratégia de produção do desenvolvimento rural do fortalecimento da agricultura familiar no Brasil, o PRONAF tem como eixos básicos o financiamento da produção agrícola, por intermédio da concessão de financiamento pelos agentes financeiros (PRONAF-CRÉDITO); a transferência de recursos orçamentários para o desenvolvimento rural de municípios selecionados (PRONAF-INFRA-ESTRURURA); e a capacitação e profissionalização dos agricultores familiares (PRONAF-CAPACITAÇÃO).

Esses eixos citados têm como objetivos aumentar a capacidade de produção do campo e a geração de renda, para os agricultores familiares, oportunizando a estes, investirem em sua produção através de créditos cedidos pelo governo. Existindo, portanto os três eixos que norteiam o programa, sendo eles: PRONAF CRÉDITO, viabiliza o financiamento para que o agricultor possa montar sua própria atividade agrícola, PRONAF ESTRUTURA, destinado às parcerias aos municípios e aos agricultores com objetivo de melhorar as estruturas físicas e maquinários já existentes possibilitando uma melhor produção e escoamento da produção.

Esse programa conta com instituições financiadoras, que trabalham em parcerias, a saber: o Banco Nacional do Desenvolvimento Econômico e Social (BNDES), o Fundo de Amparo ao Trabalhador (FAT), e

as outras fontes Fundos Constitucionais do Nordeste (FNE) e do Centro-Oeste (FCO).

O PRONAF surgiu com o objetivo de facilitar ao pequeno agricultor a oportunidade de acesso ao crédito, tendo como meta o fortalecimento da agricultura familiar. O Estado, portanto, agora oferece suporte político e econômico a este modelo de prática agrícola, que de acordo com estudos técnicos divulgados pelo IBGE em 2010, o modelo de prática de agricultura familiar é responsável por ofertar maior taxa de emprego no campo, assim como também de garantir uma variedade de alimento disponível para o consumo dos brasileiros.
Alguns pontos característicos desse modelo de agricultura é a oferta de emprego que o setor da agricultura familiar pode oferecer, pois a cada dez trabalhadores empregados no campo, cerca de oito estão em atividades ditas familiares. Segundo o Plano Safra de 2011/2012, este setor é responsável pela produção de $70 \%$ dos alimentos que chegam à mesa dos brasileiros, sendo responsável ainda por mais de $74 \%$ do pessoal empregado no campo e por $10 \%$ do Produto Interno Bruto. Esse destaque provocou o reconhecimento do Governo Federal que passou a investir mais na agricultura, por meio da liberação de créditos (para o PRONAF e seus atores), como bem coloca Silva (2008).

Para ter acesso ao PRONAF faz-se necessário que o agricultor esteja classificado na condição de agricultor familiar. Em segundo lugar, é preciso se adequar às diversas modalidades do programa, tendo em vista que o mesmo visa atingir um público amplo, diverso e com peculiaridades distintas. Para esse atendimento, o programa utiliza critérios para classificação do agricultor e a modalidade que ele deseja recorrer o financiamento: o tamanho da propriedade rural, renda anual da família e a capacidade de forragem da propriedade. Seguindo essa classificação, é montando um projeto levando em consideração a habilidade do produtor familiar, de acordo com o setor em que ele deseja aplicar seu financiamento, aplicando o projeto tal qual como foi montado, e para a eficácia isso se faz necessário um acompanhamento técnico responsável pela a equipe que montou o projeto.

São essas modalidades de PRONAF segundo Schneider (2004):

Grupo A: agricultores assentados de reforma agrária que, com a extinção do Programa Especial de Crédito para a Reforma Agrária (PROCERA), passaram a ser atendidos pelo PRONAF. Atualmente, pelas regras do Plano de Safra 2003/04, esses agricultores podem financiar até R $\$ 2.500,00$ para custeio da safra e até $\mathrm{R} \$ 13.500,00$ para investimentos. No caso de crédito de custeio, o prazo para pagamento é de dois anos e as taxas de juros são de $2 \%$ ao ano.

Grupo B: agricultores familiares e remanescentes de quilombos, trabalhadores rurais e indígenas com renda bruta anual atual até $\mathrm{R} \$ 2.0000,00$. Esse grupo inclui as famílias rurais com baixa produção e pouco potencial de aumento de produção no curto prazo localizado em regiões com concentração de pobreza rural. Os valores dos financiamentos (custeio mais investimentos) são limitados em até $\mathrm{R} \$$ 2.000,00 para qualquer atividade geradora de renda, com juros de $1 \%$ ao ano e prazo para pagamento de dois anos, sendo um de carência.

Grupo C: agricultores familiares com renda bruta anual entre $\mathrm{R} \$ 2.00,00$ a R\$ 14.00,00, que apresentem explorações intermediárias com bom potencial de resposta produtiva. Os limites de financiamento para custeio são de $\mathrm{R} \$ 2.500,00$, com juros de $4 \%$ ao ano, desconto (rebate) de $\mathrm{R} \$ 200,00$ e prazo de pagamento de até dois anos.

Grupo A/C: agricultores oriundos do processo de reforma agrária e que passam a receber o primeiro crédito de custeio após terem obtido o crédito de investimento inicial que 
substituiu o antigo programa de apoio aos assentados. Os limites de financiamento de custeio variam de $\mathrm{R} \$ 500,00$ até $\mathrm{R} \$ 2.500,00$, com juros de $2 \%$ ao ano e prazo de pagamento de até dois anos.

Grupo D: agricultores estabilizados economicamente com renda bruta anual entre $\mathrm{R} \$ 14.000,00$ e $\mathrm{R} \$ 40.000,00$, sendo que o limite para custeio é de até $\mathrm{R} \$ 6.000,00$, com juros de $4 \%$ ao ano e prazo de até dois anos.

Grupo E (PROGER Familiar Rural): agricultores com renda bruta anual entre $\mathrm{R} \$ 40.000,00$ a $60.000,00$. Os limites de financiamento para custeio são de $\mathrm{R} \$ 28.000,00$, com juros de 7,25\% ao ano e prazo de pagamento é de dois anos.

É preciso ressaltar que essas modalidades não foram criadas todas de uma só vez. Houve um surgimento gradativo que se adaptou às necessidades e aos tipos de financiamento ensejados pelos agricultores.

Essas criações se dão no intuito de que o programa atenda cada vez mais um leque de produtores rurais que possuem como fator principal a renda através da exploração de sua propriedade rural, tendo como modelo a agricultura familiar. Essas modalidades foram sendo implantadas no programa através de ementas. O objetivo do Estado, como credor e incentivador da produção e desenvolvimento no campo, é oferecer apoio ao agricultor conforme suas necessidades e modalidades de produção familiar.

Surgiram novas modalidades após o ano de 2002 Foram criadas outras, como mostra Rodrigues e Lima (2003):

PRONAF Alimentos: crédito especial de estímulos à produção de arroz, feijão, mandioca, milho e trigo, com 50\% a mais de crédito em relação à última safra de produção desses alimentos.

PRONAF Semiárido: crédito especial para agricultores da região do semiárido para construção de pequenas obras hídricas.

PRONAF Mulher: crédito 50\% superior aos dos créditos de investimento dos grupos $\mathrm{C}$ e D para projetos no campo.

PRONAF Jovem Rural: crédito 50\% superior aos créditos de investimentos dos grupos C e D para jovens entre 16 e 25 anos que estiverem cursando a partir do último ano em escolas técnicas agrícolas de nível médio.

PRONAF Pesca: crédito para pescadores artesanais com renda anual bruta familiar de até 40.000,00 para modernizar ou ampliar atividades produtivas.

PRONAF Florestal: crédito de apoio aos agricultores familiares na implantação de projetos de manejo sustentável, reflorestamento e sistemas agroflorestais.

Pronaf Agroecologia: crédito de investimento à produção agroecológica ou transição para agricultura sustentável.

PRONAF Turismo Rural: crédito para desenvolvimento de projetos de turismo rural em suas propriedades.

PRONAF Máquinas e Equipamentos: crédito voltado à modernização das propriedades familiares, com fins à melhoria da produção e produtividade.
Houve a inserção também dos eixos do PRONAF, voltados a uma maior responsabilidade ambiental. O Governo Federal disponibiliza recursos, por exemplo, para que a agricultura familiar tenha em sua produção a prática agroecológica como norteio de produção, e que a exploração dos recursos naturais seja de maneira racional pelos agricultores.

Os novos eixos do PRONAF surgiram a partir das inquietações da sociedade, de como estão sendo produzidos os alimentos que chegam a nossa mesa. Essas inquietações somadas às pressões da sociedade civil organizada provocaram o surgimento de novas modalidades no programa. Tais modalidades vêm ensejando o desenvolvimento de uma produção mais sustentável e adequada à preservação do meio ambiente. Para que isso ocorra, é preciso adotar práticas sustentáveis de produção agroecológica. Esse método pode agregar maior valor econômico ao produto, pois os alimentos estarão livres de defensivos agrícolas, reduzindo assim os impactos ambientais e melhorando a saúde humana.

O programa incentiva a redução do desmatamento e a preservação dos recursos naturais, beneficiando os agricultores que adotarem medidas de proteção ao meio ambiente. Para isso, o governo investe na conservação desses recursos naturais, com a modalidade do PRONAF Turismo Rural. Devido às transformações da sociedade e a necessidade de conscientização ecológica, os agricultores agora estão sendo incitados a voltarem um novo olhar para campo e protegerem os recursos naturais de sua propriedade, a fim de preservá-la, e terem uma nova oportunidade de renda e melhoria na sua qualidade de vida, promovendo o turismo rural.

\section{MATERIAL E MÉTODOS}

O munícipio de Aparecida está localizado, segundo o IBGE, na região Oeste do estado da Paraíba, limitando-se a Oeste com Sousa, ao Sul com São José da Lagoa Tapada, a Leste com São Domingos e ao Norte com São Francisco. Ocupa uma área de $295 \mathrm{Km}^{2}$, possuindo uma população, segundo o Censo Demográfico 2010 do IBGE, de 7.676 habitantes. O acesso à capital João Pessoa se dá pela BR 230, equidistante em cerca de $409 \mathrm{Km}$.

O método adotado para a pesquisa foi o método dialético, no qual buscou-se investigar essa nova dinâmica ocorrente no campo brasileiro, motivado pelo financiamento do Governo Federal destinado a agricultura familiar com a política do PRONAF. Isso só nos foi possível através dos seguintes procedimentos de entrevistas semiestruturadas realizadas com os promotores do PRONAF no município de Aparecida sendo eles: o Banco do Nordeste Brasileiro (BNB), Empresa de Assistência Técnica e Extensão Rural (EMATER), Central de Associações de Assentamentos do Alto Sertão Paraibano (CAAASP) e o Sindicato Rural dos Agricultores de Aparecida-PB e também através de questionários aplicados aos agricultores do assentamento Acauã e do PIVAS.

\section{RESULTADOS E DICUSSÃO}

A finalidade do PRONAF não se limita somente à obtenção de crédito, mas visa também o aprimoramento das tecnologias (renovação de maquinários, transportes e etc.). $\mathrm{O}$ 
intuito é provocar melhorias na qualidade dos produtos, tornando-os mais competitivos e com maior valor de mercado.

Os agricultores familiares podem contar também com o subsídio técnico e cursos de capacitações oferecidos aos pequenos agricultores que almejam uma melhoria em sua produção e a possibilidade de uma renda familiar mais sólida, uma vez que recorrendo ao programa o produtor familiar tem a possibilidade de ter acesso aos métodos mais adequados de produção, nas mais diversas áreas em que ele queira desenvolver seu projeto de investimento, isso, graças às palestras e à formação por instituições parceiras como: a EMATER, Sindicatos Rurais, Serviço Brasileiro de Apoio às Micro e Pequenas Empresas (SEBRAE), dentre outros.

Surgiu com o PRONAF a oportunidade de desenhar um novo cenário na história da política de incentivo à produção familiar brasileira.

O público para o qual esse projeto é voltado é aquele classificado como o pequeno agricultor que tem como renda o próprio trabalho da família em sua propriedade rural ou que tenha arrendado a terra para obter dela seu próprio sustento.

É preciso ressaltar que essas modalidades não foram criadas todas de uma só vez. Houve um surgimento gradativo que se adaptou às necessidades e aos tipos de financiamento ensejados pelos agricultores.

Essas criações se dão no intuito de que o programa atenda cada vez mais uma parcela maior de produtores rurais que possuem como fator principal a renda através da exploração de sua propriedade rural, tendo como modelo agricultura familiar. Essas modalidades foram sendo implantadas no programa através de ementas. O objetivo do Estado, como credor e incentivador da produção e desenvolvimento para campo, é oferecer apoio ao agricultor conforme suas necessidades e modalidades de produção familiar.

O Governo Federal oferece diversas modalidades de programa, com o objetivo de atender a maioria dos agricultores, facilitando o acesso ao financiamento e investindo em sua produção, para assim, fortalecer seu potencial produtivo.

Essas modalidades foram sendo implantadas no programa gradativamente, buscando suprir as necessidades e as variadas práticas agrícolas desenvolvidas pelos agricultores. Esse é o objetivo do Governo Federal, assistir a um número cada vez maior de agricultores, independentemente de sua modalidade agrícola, possibilitando ao chefe de família (seja do sexo masculino ou feminino) o sustento e a qualidade de vida da família.

Para isso, o programa ganhou novas linhas de financiamentos, apresentando versões mais ecológicas e incluindo em suas modalidades os incentivos às novas práticas agrícolas e ecológicas.

A valorização das potencialidades naturais locais das regiões brasileiras também é contemplada no programa. Isso no intuito de permitir com que o agricultor familiar tenha a possibilidade de explorar esses recursos de forma mais consciente e segura, arrecadando financiamento para sua permanência no local onde vivem.

Essas inovações que vem ocorrendo no PRONAF desde sua criação busca assistir não só o agricultor, mas também para sua família como um todo. Deste modo, o programa também busca beneficiar aos jovens do campo, oferecendo-lhes a oportunidade de financiamento. Com isso, eles podem investir no próprio campo, em suas atividades diárias junto com sua família, e consequentemente, terem sua própria renda. Essa ação tem o objetivo de reduzir o êxodo rural dos jovens para os grandes centros urbanos do país.

No município de Aparecida, segundo informações do coordenador do PRONAF e funcionário do BNB, agência de Sousa-PB, a modalidade do programa que é mais trabalhada é o microcrédito rural do tipo PRONAF $\mathrm{B}$, linha de crédito que oferece para o agricultor familiar o financiamento com valor de ate 2.500 reais, para família que comprovar a renda anual de até 6 mil reais.

O município possui dois grandes potenciais que ainda estão a ser explorados, segundo o próprio coordenador do BNB: O primeiro potencial a ser explorado no município é a implantação e expansão em escala maior da modalidade de PRONAF. Isso devido ao número de assentamentos rurais que o mesmo possui hoje, um total de quatro, e mais oito acampamentos, em que em breve estes se tornarão assentamentos, somarão juntos, doze assentamentos, contendo mais de mil assentados.

O segundo setor que começa despontar no município é o Perímetro Irrigado Várzeas de Sousa (PIVAS), com a produção de grãos para exportação e iniciou-se recentemente a produção de fruticultura irrigada. $O$ projeto teve início no ano de 2002, na gestão do ex-governador José Targino Maranhão, tendo como meta impulsionar a economia do Estado, dinamizando assim sua produção agrícola tornando-a mais atrativa para as empresas do agronegócio, e despertando nestas, o interesse em produzir nesta região, investindo em seu potencial natural com terras férteis e sol durante o ano todo.

\section{CONSIDERAÇÕES FINAIS}

Percebe-se que no campo ainda há uma insatisfação dos agricultores devido à falta de acompanhamento técnico, ficando os agricultores desassistidos. Para que se reverta esse quadro é preciso unir forças. São esforços no intuito de que o agricultor familiar seja o maior beneficiado dessa união, uma vez que passou tantos anos desacreditados de sua importância pelo poder público, tenha nesse programa, a oportunidade de mudar realmente a realidade do campo, principalmente na região do alto sertão paraibano que enfrenta as adversidades climáticas que assolam o homem do campo.

Faz-se necessário também a realização de cursos de capacitação para os agricultores, principalmente nas áreas onde eles investiram os financiamentos. Essa capacitação deve ser acompanhada de uma formação técnica, com métodos e práticas inovadoras, para que o agricultor (que geralmente não teve a oportunidade de uma formação durante a sua juventude) possa ser capacitado na prática.

\section{REFERÊNCIAS BIBLIOGRÁFICAS}

BRASIL. LEI No 11.326, DE 24 DE JULHO DE 2006. Estabelece as diretrizes para a formulação da Política Nacional da Agricultura Familiar e Empreendimento Familiar Rural. Disponível em<http://www.planalto.gov.br/ccivil_03/_ato20042006/2006/lei/111326.htm . Acesso em: 23/10/2012. 
FERRAZ, Osni Giani; et al. Microcrédito rural: Análise sobre a modalidade do PRONAF B. Ministério do meio ambiente- DF- Brasil. Rio Branco Acre 2008. Disponível

em<http://ageconsearch.umn.edu/bitstream/107936/2/72 5.pdf.> Acesso em: 06/10/2014.

INSTITUTO Brasileiro de Geografia e Estatística. Dados básicos do município de Aparecida., 2010. Disponível em:<http://www.ibge.gov.br/cidadesat/painel/painel.php ?codmun=250077\#>Acessado em: 04/11/2014.

INSTITUTO Brasileiro de Geografia e Estatística. História de Aparecida - PB. Disponível em: http://biblioteca.ibge.gov.br/. Acesso em:> 20/12/2014.

MATTOS, Eloisa de Hofling, Estado e Políticas (Públicas) Sociais. Cadernos Cedes, ano XXI, N55, NOVEMBRO / 2001. Disponível em:< http://www.scielo.br/pdf/ccedes/v21n55/5539.pdf.Acess o em: 30/08/2014.

MINISTÉRIO Desenvolvimento Agrário. Plano safra da agricultura familiar 2011/2012 disponibiliza $R$ \$ 250 milhões para a Paraíba. 30/06/2011. Disponível em: www.mda.gov.br/planosafra/news/item?item_id=80964 07.> Acesso em: 05/07/2014.

PROJETO de irrigação Várzea de Sousa. Informação posta no site do governo da Paraíba no link, Agropecuária e Pesca - Programas e Ações. Disponível em:< http://www.paraiba.pb.gov.br/agropecuaria-epesca/programas-e-acoes.>Acessado em: 25/10/2014.

RODRIGUES, M. F. F; LIMA, Aline Barbosa de. A agricultura Familiar sob a Ótica do Estado: uma leitura do PRONAF na Paraíba. In: I simpósio Internacional de Geografia Agrária, 2003, São Paulo. O campo no século XXI. São Paulo: Universidade de São Paulo (USP), 2003. p. 1-11. Disponível em: <http://www.biblioteca.sebrae.com.br/bds/bds.nsf/539c4 19282fa9e2b03256d50006891ad/8466b0d2b6cdbcbf032 570440074b265/\$FILE/agricultura\%20familiar.pdf.> Acessado em: 04/06/2014.

SCHEIDER, Sergio; SILVA, Marcelo Kunrath; MARQUES, Paulo Eduardo Moruzzi (Org). Histórico, caracterização e dinâmica recente do PRONAFPrograma Nacional de Fortalecimento da Agricultura familiar: Porto Alegre, 2004, p21-50 Disponível em: $<$ http://www.ufcg.edu.br/downods/schnceder/historicopronaf.pdf.>acessado em: 28/09/2014.

SILVA, Aldenir Gomes da. Financiamento rural: dos objetivo ás escolhas efetivas. Porto Alegre: Sulina, 2008,167p.

SILVA, Enid Rocha Andrade da. Texto para discussão ${ }^{\circ}$ 664. Programa nacional de fortalecimento Relatório das ações desenvolvidas no período 1995/1998. Brasília, agosto de 1999. Disponível em:<
http://www.ipea.gov.br/pub/td/td_99/td_664.pdf.>Acess o em: $15 / 08 / 2014$. 